\title{
EFL students' attitudes towards learner autonomy in English vocabulary learning
}

\author{
Thao Quoc Tran ${ }^{\mathrm{a}, 1, *}$ \\ ${ }^{a}$ Ho Chi Minh City University of Technology (HUTECH), 475 A Dien Bien Phu Street, Ward 25, Binh Thanh District, Ho Chi Minh City, Vietnam \\ ${ }^{1}$ tq.thao@hutech.edu.vn* \\ * corresponding author
}

ARTICLE INFO

\section{Article history}

Received 22 June, 2020

Revised 03 August, 2020

Accepted 25 August, 2020

Keywords

Attitude

English major

English vocabulary learning

higher institution

learner autonomy

\section{ABSTRACT}

Whether EFL learners can use English well or not depends much on vocabulary they possess. Learner autonomy (LA), however, plays a pivotal role in amassing EFL learners' vocabulary. This study endeavored to explore students' attitudes towards LA in English vocabulary learning. Two hundred English majors from a Ho Chi Minh City based higher institution, Vietnam got involved in answering the closed-ended questionnaire, and ten students took part in semistructured interviews. The findings indicated that participants were cognitively aware of the importance of LA in English vocabulary learning, but affectively and behaviorally they showed low interest in LA in English vocabulary learning. Such findings may shed light on how to improve the teaching and learning of the English language in general and English vocabulary in particular at the research context and other similar EFL contexts.

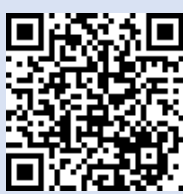

This is an open access article under the CC-BY-SA license.

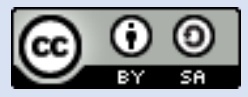

\section{Introduction}

Many researchers (e.g., Nation, 2001; Richards \& Renandya, 2002; Schmitt, 2010) have claimed that vocabulary is one of the most important components of language learning in which learners are able to use it in order to support for four language skills. Likewise, Balci and Çakir (2011) have confirmed that vocabulary plays a vital role in any stages of the learners' language development. Moreover, it is impossible for a learner to communicate without the required vocabulary. Indeed, a number of scholars (e.g., Willis, 1990; Lewis, 1993; Folse, 2004) in the field of vocabulary believe that communication can occur without syntax and grammar, but not vocabulary. As such, it cannot be denied that if learners have no vocabulary, they cannot express their ideas, thinking or feelings as well as are unable to understand the meaning of written and spoken texts. Thus, vocabulary learning is a prominent domain to approach a satisfactory language proficiency level (Boers \& Lindstromberg, 2008).

The concept of learner autonomy (LA) has generally been focused as an alternative approach (e.g, Gremmo \& Riley, 1995; Benson, 2001; Duong \& Seepho, 2013, 2014; Duong, 2015; Tran \& Vo, 2019), and it has been emphasized in educational environments and particularly in language learning (e.g., Holec, 1981; Dickinson, 1995; Little, 1991; Benson, 2003). McDevitt (1997) states that "the end product of language learning is an independent learner" in every aspect of the language" (p. 34). Therefore, vis-à-vis the aspect of vocabulary, helping learners to learn how to learn vocabulary autonomously is an immensely important element which ESL/EFL teachers have to take into account in teaching.

Nevertheless, in the Vietnamese context as well as other EFL ones, it is noticed that the matter of LA in English vocabulary learning is not yet much emphasized (e.g., Duong, 2015; Tran \& Nguyen, 2017). Many EFL learners are still educated with the passive style along with the teacher-centered belief (Nguyen, 2014), and their proficiency in vocabulary today is still poor as they focus on 
memorizing a long list of English vocabulary provided by EFL teachers (Nguyen, 2013). In addition, learners are spoon-fed with vocabulary rather than learning the vocabulary independently (e.g., Duong, 2015; Tran \& Nguyen, 2017). Therefore, this study endeavors to explore the students' attitudes toward LA in English vocabulary learning at the context of a Ho Chi Minh-based higher institution, Vietnam. The research question is 'What are English majored students' attitudes towards LA in English vocabulary learning at a Ho Chi Minh-based higher institution?"

The notion of LA has been differently defined by scholars and researchers (e.g., Holec, 1981; Little, 1991; Littlewood, 1996; Macaro, 1997; Benson, 2001; Vanijdee, 2003). Holec (1981) defines LA as the ability of learners to take charge of one's own learning. Likewise, Littlewood (1996) defines LA as "learners' ability and willingness to make choices independently" (p. 427). In addition, Macaro (1997) states that LA is "an ability to recognize the value of taking responsibility for [...] learning" (p. 168). In the same vein, Benson (2001) highlights that LA is "the capacity of taking control of learning management, learning content" (p. 47), and other researchers (e.g., Duong \& Nguyen, 2018; Tran \& Duong, 2018; Tran, 2018; Tran \& Vo, 2019) have pinpointed that LA as a complicated process in which learners must become more active and independent agents of language classrooms and even outside classrooms in different arenas such as selecting extra materials, selecting learning strategies, and self-evaluating their learning outcomes. In short, there are different ways to define learner autonomy. Within the scope of this study, LA is considered as learner's willingness and ability to take responsibility for his/her own learning.

Vocabulary learning is one of the major challenges faced by language learners (Ghazal, 2007), and it is impracticable for a learner to communicate without the necessary vocabulary items. However, a learner cannot learn all vocabulary in language classes, so he/she must seek other useful ways to help her acquire language vocabulary in the best way. LA is an extreme support for learners in vocabulary learning because it provides many advantages for learners (Gu \& Johnson, 1996) as follows. LA not only enhances the learner's motivation to help them learn vocabulary more effectively but also accommodates learners with more opportunities for language communication. In addition, it caters to the individual needs and abilities of learners as well. Moreover, it heightens the learners' readiness towards active learning and helps them become more self-confident. In another aspect, according to Nada (2015), LA is very valuable because of two following reasons. The first reason is that LA helps students to develop their learning. The next reason is that it helps them to become interactively motivated learners. Therefore, the importance of LA in language learning process is undeniable. During that process, attitude is the core element that helps to build LA. According to Qui and $\mathrm{Li}$ (2006), positive attitudes are considered as a crucial factor which leads to the success of the development of LA.

Attitude is defined as "a psychological tendency that is expressed by evaluating a particular entity with some degree of favor and disfavor" (Eagly \& Chaiken, 1993, p. 1), and it is composed of three components, namely cognitive, affective and behavioral components (Luu, 2011). According to Kara (2009), learners' attitude has an important impact on their behaviors as well as on their performance. Attitude can shape the way students think, understand, feel and behave. In other words, it is believed that attitude shapes all decisions and actions (e.g., Brown, 2001; Eagly \& Chaiken, 1993; Tran, Duong \& Huynh, 2019; Tran \& Seepho, 2016; Tran \& Tran, 2017). Richardson (1996) asserts that "Attitudes and beliefs are a subset of a group of constructs that name, define, and describe the structure and content of mental states that are thought to drive a person's actions" (p.102). Furthermore, Dörnyei (2007) states that not only intellectual capacity but also attitudes do contribute to the success of language learning. More academically, Ellis (1994) mentions that learners' attitudes have been identified as an important variable on learning outcome. There are two tendencies of attitudes, i.e. positive and negative ones. A student who has a positive attitude towards a target language will attempt to do well in the classroom and study hard. In contrast, negative attitudes can impede language learning continuity.

Prior studies have shown that research on different areas of LA in English language learning has been conducted. In respect of attitudes towards LA in English language learning, many researchers (e.g., Chan, 2001; Joshi, 2011; Mohamadpour, 2013; Chen \& Pan, 2015; Sedighi \& Tamjid, 2016) have conducted studies on this area. Remarkably, Chan (2001) investigated the degree of LA from the learner perspective in Hong Kong. Her research explored the learners' attitudes of language learning, teacher and learner roles, their learning preferences and perception of learner autonomy. To achieve the aims of her research, 20 second-year English majored students in Polytechnic 
University were asked to fill in four questionnaires. The findings revealed that the participants had a positive attitude towards autonomous learning. In addition, they had a clear understanding of learner autonomy and the role of the teacher. Chen and Pan (2015) carried out a survey with the use of questionnaire on students in a junior high school in central Taiwan. Findings from 130 ninth-grade students revealed that the students held positive attitude towards autonomous in language learning, however, they are medium autonomous learners. The researchers also found that there was a correlation between learners' learning autonomy levels and the use of language learning strategies.

In the context of Vietnam, researchers (e.g., Luu, 2011; Le, 2013; Duong \& Seepho, 2014; Nguyen, 2014) have conducted studies on learners' language learning strategies in general and vocabulary learning in specific. Luu (2011) carried out his study at University of Finance-Marketing to investigate learners' attitudes toward vocabulary learning autonomy and strategies they utilized in vocabulary learning. The participants belonged to two groups. The first group consisted of 140 first year students from four pre-intermediate English classes. The second group consisted of 13 teachers. The findings indicated that although the students found their vocabulary very poor, and understood the importance of vocabulary learning autonomy, they still did not have a good habit of autonomous vocabulary learning. They even had low intrinsic motivation to learn and their confidence level for vocabulary learning is also not high. They thought that vocabulary learning was hard and they self-assessed their ability for the skill as rather low. For learning strategies, the students reported high familiarity to using bilingual dictionary, asking for L2-L1 translation, spoken repetition and word list for vocabulary retention. Le (2013) did a study on students' belief about and performance of LA, and designed an integration between learner training with language courses of Listening and Speaking 3 at a private university in Ho Chi Minh City, Vietnam. The findings indicated the major perception of LA relevant to taking initiative in self-study and some hindering factors such as time constraints, a stringent syllabus, and relationship between teachers and students.

It is noticed that different studies have been conducted exploring various aspects of LA in English language learning; however, the research area on attitudes towards LA in English vocabulary learning seems not to be much focused. Therefore, there is a niche for this current study which aims at exploring attitudes towards LA in English vocabulary learning of English majors at a higher institution in Ho Chi Minh City, Vietnam.

\section{Method}

\subsection{Research location and participants}

This mixed methods study was conducted at a higher institution located in Ho Chi Minh City, Vietnam. The research participants were 200 first and second-year English majored students who were purposively sampled to answer the questionnaire. Table 1 indicates that there were 88 male students $(44 \%)$ and 122 female students $(56 \%)$. In respect of the number of hours of learning English vocabulary, over a half of the students $(68.5 \%)$ spent less than one-hour, while a very small number of students $(2 \%)$ allocated more than two hours to learning vocabulary daily. In addition, $17 \%$ of whom spared about one hour, and $12.5 \%$ of students spent from one to two hours. Of 200 participants, ten students were purposively invited for semi-structured interview. They were chosen based on their volunteering and number of daily vocabulary learning hours.

Table 1. Research Participants' General Information

\begin{tabular}{|c|c|c|c|c|}
\hline \multirow{2}{*}{ No. } & \multirow{2}{*}{ Information } & & \multicolumn{2}{|c|}{$\mathrm{N}=200$} \\
\hline & & & $\mathbf{F}$ & $\%$ \\
\hline \multirow[b]{2}{*}{1} & \multirow[b]{2}{*}{ Gender } & Male & 88 & 44.0 \\
\hline & & Female & 112 & 56.0 \\
\hline \multirow{4}{*}{2} & \multirow{4}{*}{ Number of daily hours of learning English vocabulary } & Less than 1 hour & 137 & 68.5 \\
\hline & & About 1 hour & 34 & 17.0 \\
\hline & & $1-2$ hours & 25 & 12.5 \\
\hline & & More than 2 hours & 4 & 2.0 \\
\hline
\end{tabular}

Note: F: frequency; \%: Percent 


\subsection{Research instruments}

Two research instruments, viz. closed-ended questionnaire and semi-structured interview, were employed for data collection. The questionnaire consists of two parts: Part A asking the respondent's background information; Part B (main content) asking the respondent's attitudes towards LA in English vocabulary learning. The main content which was adapted from Luu (2011) includes 12 closed-ended items with five-point Likert scale (from Strongly disagree to Strongly agree). Items 1 to 8 are for the significance of autonomous English vocabulary learning (cognitive component), while Items $9-12$ are for interest in autonomous English vocabulary learning (affective \& behavioral components). The questionnaire was translated into Vietnamese so that respondents did not encounter any language difficulty in answering the questionnaire. The Cronbach's alpha value of the whole questionnaire was .79, which means that the reliability of the questionnaire was high. The semi-structured interview includes three main questions for in-depth information on participants' attitudes towards LA in English vocabulary learning. The interviews were conducted in Vietnamese so that learners could express their ideas and thinking fully.

\subsection{Procedures for data collection and analysis}

With respect to data collection, the official questionnaire and interview protocol were conducted after they had been piloted. The questionnaires were administered to respondents in person, and instruction was conducted. It took the respondents approximately 15 minutes to finish the questionnaire. The questionnaires were returned after that. Then, ten students were invited for faceto-face semi-structured interview. The interviews were conducted at break time and after class. The interview protocol was explained to interviewees. Each interview lasted from 20 to 25 minutes. All the interviews were recorded for later analysis.

Regarding data analysis, the quantitative data from questionnaires were analyzed by SPSS in terms of descriptive statistics, while the qualitative data from interviews were analyzed by the content analysis approach. The interval scores of the five-point Likert scale were interpreted as 1.00 - 1.80: strongly disagree; $1.81-2.60$ : disagree; 2.61 - 3.40: neutral; $3.41-4.20$ : agree; $4.21-5.00$ : strongly agree. The interviewees were coded as S1, S2 to S10. In order to make sure that qualitative data analysis was valid and reliable, two researchers in the field of English language studies were invited to re-analyze the three randomly chosen pieces of data. The percentage of convergent results among researchers should be at least $95 \%$.

\section{Finding and Discussion}

\subsection{Finding}

1) English majored students' attitudes towards LA in English vocabulary learning

As can be seen from Table 2, the overall mean score of English majored students' attitudes towards LA in English vocabulary learning is 3.42 (out of 5). Particularly, the mean score of the significance of autonomous English vocabulary learning was very high (Group 1: $\mathrm{M}=4.32, \mathrm{SD}=$ .44); however, the mean score of the interest in autonomous English vocabulary learning was relatively low (Group 2: $\mathrm{M}=2.51, \mathrm{SD}=.92$ ). It can be indicated that cognitively, the participants were well aware of the importance of autonomous English vocabulary learning, but affectively and behaviorally they were not much interested and engaged in learning English vocabulary autonomously.

Table 2. English Majored Students' Attitudes towards LA in English Vocabulary Learning

\begin{tabular}{crrrr}
\hline \multirow{2}{*}{ No. } & & \multicolumn{2}{c}{$\mathrm{N}=\mathbf{2 0 0}$} \\
\cline { 3 - 4 } & & $\mathrm{M}$ & $\mathrm{SD}$ \\
\hline 1 & Cognitive component & 4.32 & .44 \\
2 & Affective and behavioral components & Total & 2.51 & .92 \\
& & 3.42 & .51 \\
\hline
\end{tabular}

Note: M: Mean; SD: Standard Deviation 
2) English majored students' attitudes towards LA in English vocabulary learning in terms of cognitive component

The results in Table 3 illustrate the significance of autonomous English vocabulary learning. Cognitively, the participants strongly agreed that autonomous English vocabulary learning "is necessary" (Item 2: $\mathrm{M}=4.60, \mathrm{SD}=.62$ ) and "plays an important role in English language learning" (Item 1: $\mathrm{M}=4.32, \mathrm{SD}=.74)$. In addition, they strongly believed that autonomous English vocabulary learning could help them to improve their language skills, i.e., speaking skill (item 4: M $=4.21, \mathrm{SD}=.69$ ), listening skill (Item 5: $\mathrm{M}=4.35, \mathrm{SD}=.88$ ), reading skill (Item $6: \mathrm{M}=4.52, \mathrm{SD}=$ .69 ), writing skill (Item 7: $\mathrm{M}=4.37, \mathrm{SD}=.78$ ) and to understand English grammar (Item 8: $\mathrm{M}=$ 4.36, SD = .79). However, the participants were in agreement that autonomous English vocabulary learning "helps [them] to develop my English language proficiency" (Item 3: M = 4.07, SD = .89).

Table 3. English Majored Students' Attitudes towards LA in English Vocabulary Learning in Terms of Cognitive Component

\begin{tabular}{llrc}
\hline \multirow{2}{*}{ No. } & \multicolumn{2}{c}{ Autonomous English vocabulary learning... } & \multicolumn{2}{c}{$\mathrm{N}=\mathbf{2 0 0}$} \\
\cline { 3 - 4 } & & $\mathrm{M}$ & $\mathrm{SD}$ \\
\hline 1 & plays an important role in English language learning. & 4.32 & .74 \\
3 & is necessary in English language learning. & 4.60 & .62 \\
4 & helps me to develop my English language proficiency. & 4.07 & .89 \\
5 & helps me to improve my speaking skill. & 4.21 & .89 \\
6 & helps me to improve my listening skill. & 4.35 & .88 \\
7 & helps me to improve my reading skill. & 4.52 & .69 \\
8 & helps me to improve my writing skill. & 4.37 & .78 \\
\hline
\end{tabular}

Note: M: Mean; SD: Standard Deviation

Qualitatively, the findings from the semi-structured interviews showed a consistent tendency with those of questionnaires that interviewees highlighted the importance and necessity of autonomy in English vocabulary learning. They shared as follows:

I think that autonomous English vocabulary learning is very important because it helps me understand new words which I learned in class more carefully and from that it also helps me comprehend and remember the previous lessons in general and vocabulary in particular better. (S2)

I think learner autonomy is extremely vital and necessary in not only learning vocabulary but also in learning other English skills such as listening, speaking, reading and writing skills. I recognize that the help from friends and English teachers is very helpful, but they are not always available to help me at any time. (S1)

To me, autonomous English vocabulary learning is very significant because I think the more I self-learn vocabulary, the better English I will have. (S4)

3) English majored students' attitudes towards LA in English vocabulary learning in terms of affective and behavioral components

As shown in Table 4, it is noticed that the participants did not have clear affective attitudes towards whether they found it "interesting to learn English vocabulary autonomously" (Item 9: $\mathrm{M}=$ $2.64, \mathrm{SD}=1.17$ ) and "enjoyable to learn English vocabulary autonomously" (Item 10: $\mathrm{M}=2.73, \mathrm{SD}$ $=1.04)$. Regarding behavioral component, they did not "set the goals for autonomous English vocabulary learning" (Item 11: $\mathrm{M}=2.39, \mathrm{SD}=1.03$ ), and they did not "often prepare vocabulary before class" (Item 12: $\mathrm{M}=2.28, \mathrm{SD}=1.06$ ). Regarding the standard deviation scores of items 9, 10,11 and 12, they are relatively large, which means participants' answers to the mentioned items were scattered. 
Table 4. English Majored Students' Attitudes Towards LA in English Vocabulary Learning in Terms of Affective and Behavioral Components

\begin{tabular}{clcc}
\hline \multirow{2}{*}{ No. } & & \multicolumn{2}{c}{$\mathrm{N}=\mathbf{2 0 0}$} \\
\cline { 3 - 4 } & & $\mathrm{M}$ & $\mathrm{SD}$ \\
\hline 9 & I find it interesting to learn English vocabulary autonomously. & 2.64 & 1.17 \\
10 & I find it enjoyable to learn English vocabulary autonomously. & 2.73 & 1.04 \\
11 & I set the goals for autonomous English vocabulary learning. & 2.39 & 1.03 \\
12 & I often prepare vocabulary before class. & 2.28 & 1.06 \\
\hline
\end{tabular}

Note: M: Mean; SD: Standard Deviation

The findings from the semi-structured interview exhibited some similar trends as those of the questionnaire. For example, some students said that:

It is very difficult for me to learn vocabulary autonomously after class. Although most of the students are advised to learn vocabulary autonomously by our teacher, we do not know how to do it. Therefore, I usually only set the time to learn vocabulary only before tests or exams. (S3)

I admit that I am not interested in learning vocabulary. I know that it is very important, but to me, but learning vocabulary is very boring. (S2)

I hate learning vocabulary because I do not know how to learn it effectively and fast. I found it difficult to learn vocabulary autonomously after class without the help and instruction of my English teachers. (S5)

In addition, infrequent planning of any specific goals for vocabulary learning was also found in the interview results. For instance,
I don't set any goals for my learning vocabulary. I am not good at English. I just wish to pass the exams. (S7)
To tell you the truth, I seldom plan any specific goals for my vocabulary learning. After class, I have to study other classes and do a lot of homework. Thus, I often concentrate on learning it in my free time when my English teacher asks me or before important English exams or tests. (S10)

\subsection{Discussion}

This study revealed some significant points. Participants, in general, had positive attitudes towards LA in English language learning. This finding is in alignment with that in previous studies (e.g., Chan, 2001; Chen \& Pan, 2015) which have significantly asserted that the students held positive attitudes towards LA in learning English in general and English vocabulary learning in particular. This is viewed as a favorable condition which can strengthen the teachers' efforts and beliefs in teaching vocabulary to their students. In other words, English majored students' positive attitudes towards learning English vocabulary autonomously can be considered as a powerful motivating source for students to pay serious attention to vocabulary learning.

Cognitively, participants perceived that LA played important roles in English vocabulary learning. This piece of evidence may show that the EFL high school students were ready to take responsibility for their own English vocabulary learning. This finding was confirmed by the results from Sedighi and Tamjid (2016) who found out that the respondents were willing and capable of taking responsibility for their own learning. Conversely, the findings from Mohamadpour (2013) found out that the awareness of EFL students of learner autonomy and their readiness to become autonomous learner were relatively low. One of the possible explanations may be that the participants were English majored students who had learned English for many years. That is why they were well aware of the importance of English vocabulary learning, and perceived the importance of LA in English vocabulary learning in order to improve their English language skills.

Notwithstanding, the participants had neutral affective attitudes towards LA in English vocabulary learning, and they had negative behavioral attitudes towards LA in English vocabulary 
learning. In another aspect, many of the participants may have had positive affective attitudes as the standard deviation scores were not convergent. Such findings contradict their cognitive attitudes towards LA in English vocabulary learning. It can be understood that although the participants believed that LA in English vocabulary learning was very important and useful to improve their English, they seemed to be quite reluctant to perform it. There are some possible explanations for such findings. The first reason may be that many participants may find learning English vocabulary independently boring, and they may have a tendency of dependence on their teacher who can supply them with new words in each lesson. The second reason may be due to the fact that participants were first- and second-year students, so they did not know how to use vocabulary learning strategies appropriately. The next reason may be that participants were not autonomous in learning as the fact shows that nearly $70 \%$ of the participants reported that they allocated less than one hour to learning English vocabulary daily. These findings are consistent with Joshi's (2011) finding which found that although the learners were ready to take responsibility for their own language learning, they had tendency to accept the teachers' power and authority in the learning process, and they are supported by the finding of Sedighi and Tamjid (2016) who have found that when students explored appropriate language learning strategies, they could develop their autonomy gradually through individual selection and application of different words in various circumstances. This may imply that there seems to exist a gap between participants' awareness of LA English vocabulary learning and their emotion and action of autonomous English vocabulary learning. The implication seems to be consistent with the result from Luu (2011) which has shown that students were clearly aware of the role of autonomy in learning vocabulary; however, their level of interest in broadening their English vocabulary knowledge was only neutral.

\section{Conclusion}

Some conclusions can be drawn up in this study. Participants perceived that LA played important roles in learning English and improving their English proficiency, but some participants were in favor of LA in English vocabulary learning affectively and behaviorally. A gap exists between participants' cognitive attitudes towards LA in English vocabulary learning and their affective and behavioral attitudes towards LA in English vocabulary learning.

Such conclusions can suggest some implications. The findings showed that although students were well aware of the importance of LA in English vocabulary learning, their interest (affective and behavioral attitudes) in English vocabulary learning was low. Hence, it is imperative that teachers should motivate students and show them how to learn vocabulary independently by learning vocabulary by listening to English songs and watching English captioned movies. Additionally, students should be encouraged to make plans, set goals and manage their learning as well as selfevaluate their English vocabulary learning. Along with that, teachers should get involved in monitoring and checking their students' English learning process in general and English vocabulary learning in specific. This small-scale study is subject to some limitations. First, this study focuses on only one aspect of LA in English language learning. Secondly, this study involved only first and second year students. Hence, it is recommended that further research should include a wide range of students so that the results can be generalized to larger populations.

\section{References}

Balci, Ö., \& Çakir, A. (2012). Teaching vocabulary through collocations in EFL classes: The case of Turkey. International Journal of Research Studies in Language Learning, 1(1), 21-32. DOI: 10.5861/ijrs1l.2012.v1i1.31

Benson, P. (2001). Teaching and researching autonomy in language learning. London: Longman.

Benson, P. (2003). Learner autonomy in the classroom. In D. Nunan (Ed.), Practical English language teaching (pp. 289-308). New York: Mcgraw Hill.

Boers, F., \& Lindstromberg, S. (2008). How cognitive linguistics can foster effective vocabulary teaching in F. Boers \& S. Lindstromberg (Eds.), Applications of cognitive linguistics: Cognitive linguistic Approaches to teaching vocabulary and phraseology (pp.1-61). Berlin: Mouton de Gruyter. 
Chan, V. (2001). Learning Autonomously: The learners' perspectives. Journal of Further and Higher Education, 25(3), 285-300. DOI: 10.1080/03098770120077649

Chen, H. L., \& Pan, H. H. (2015). Learner autonomy and the use of language learning strategies in a Taiwanese Junior High School. Journal of Studies in Education, 5(1), 52-64. DOI: $10.5296 /$ jse.v5i1.6972

Eagly, A. H., \& Chaiken, S. (1993). The psychology of attitudes. Orlando, FL, US: Harcourt Brace Jovanovich College Publishers.

Brown, J. D. (2001). Using Surveys in Language Programs. Cambridge, UK: Cambridge University Press.

Ellis, R. (1994). The study of second language acquisition. Oxford: Oxford University Press.

Dickinson, L. (1995). Autonomy and motivation: A literature review. System, 23, 165-174. DOI: $10.1016 / 0346-251 \times(95) 00005-5$

Dörnyei, Z. (2007). Research methods in applied linguistics. New York: Oxford University Press.

Duong, T. M. (2015). A Portfolio-Based learner autonomy development model in an EFL writing course (Doctoral dissertation). Thailand: Suranaree University of Technology.

Duong, T. M., \& Nguyen, T. T. T. (2018). The role of learner autonomy in language education. Proceedings of the International Conference on Language Teaching and Learning Today 2018, held at Ho Chi Minh City University of Technology and Education. HCMC: UTE.

Duong, T. M., \& Seepho, S. (2013). EFL teachers' perceptions of promoting learner autonomy in a Thai EFL context. Paper presented at CULI's International seminar 2013, Bangkok, Thailand. Retrieved from http://www.culi.chula.ac.th.

Duong, T. M., \& Seepho, S. (2014). Promoting learner autonomy: A qualitative study on EFL teachers' perceptions and their teaching practices. Proceedings of the International Conference: DRAL 2 / ILA 2014, held at King Mongkut's Institute of Technology Thonburi, Bangkok, Thailand (pp. 129-137). Bangkok: KMITT.

Folse, K. S. (2004). Vocabulary myths: Applying second language research to classroom teaching. Ann Arbor, MI: University of Michigan Press.

Ghazal, L. (2007). Learning vocabulary in EFL contexts through vocabulary learning strategies. Novitas-Royal, 1(2), 84-91

Gremmo, M-J. \& Riley, P. (1995). Autonomy, self-direction and self-access in language teaching and learning: the history of an idea. System, 23(2), 151-164. DOI: 10.1016/0346-251x(95)00002-2

Gu, Y. Q., \& Johnson, R. K. (1996). Vocabulary learning strategies and language learning outcomes. Language Learning, 46, 643-679. DOI: 10.1111/j.1467-1770.1996.tb01355.x

Holec, H. (1981). Autonomy in Foreign Language Learning. Oxford: Pergamon.

Joshi, K. R. (2011). Learner perceptions and teacher beliefs about learner autonomy in language learning. Journal of NELTA, 16, 13-29.

Kara, A. (2009). The effect of a 'learning theories' unit on students' attitudes towards learning. Australian Journal of Teacher Education, 34(3), 100-113. DOI: 10.14221/ajte.2009v34n3.5

Le, X. Q. (2013). Fostering Learner Autonomy in Language Learning in Tertiary Education: An intervention study of university students in Hochiminh city, Vietnam. Ph.D. thesis, Nottingham University.

Lewis, M. (1993). The lexical approach. Hove, UK: Language Teaching Publications.

Little, D. (1991). Learner autonomy 1: Definitions, issues and problems. Dublin: Authentik.

Littlewood, W. (1996). Autonomy: An anatomy and a framework. System, 24(4), 427-435. DOI: $10.1016 / \mathrm{s} 0346-251 \times(96) 00039-5$

Luu, T. T. (2011). An Empirical research on self-learning vocabulary. Theory and Practice in Language Studies. 1(2), 1688-1695. DOI: 10.4304/tpls.1.12.1688-1695

Macaro, E. (1997). Target language, collaborative learning and autonomy. Clevedon: Multilingual Matters.

McDevitt, B. (1997). Learner autonomy and the need for learner training. Language Learning Journal, 16, 34-39. DOI: $10.1080 / 09571739785200251$ 
Mohamadpour, P. (2013). Realization of autonomy and English language proficiency among Iranian high school students. Theory and Practice in Language Studies, 3(7), 1187-1193. DOI: $10.4304 /$ tpls.3.7.1187-1193

Nada, J. A. (2015) Investigating EFl learner' attitudes towards using information technology. Eugene, Oregon: International Society for technology in Education.

Nation, P. (2001). Learning vocabulary in another language. New York: Cambridge University Press.

Nguyen, N.T. (2013). The Effects of Semantic Mapping on Vocabulary Memorizing. Proceedings of the 3rd International Conference on Foreign Language Learning and Teaching, Bangkok, Thailand.

Nguyen, N. T. (2014). Learner autonomy in language learning: Teachers' beliefs (Unpublished doctoral thesis). Queensland University of Technology.

Qui. S \& Li. Q. (2006). A survey on English majors attitudes towards learner autonomy. Celea Journal, 29 (5), 66-74.

Richards, J. C., \& Renandya, W. A. (2002). Methodology in language teaching: An anthology of current practice. Cambridge, England: Cambridge University Press.

Richardson, V. (1996). The role of attitudes and beliefs in learning to teach. In J. Sikula (Ed.), Handbook of research on teacher education, 2nd ed. (pp. 102-119). New York: Macmillan.

Schmitt, N. (2010). Researching vocabulary: A vocabulary research manual. Basingstoke, England: Palgrave Macmillan.

Sedighi, E., \& Tamjid, N. H. (2016). The relationship between Iranian EFL learners' autonomy and their vocabulary learning strategies with a focus on gender. The Journal of Applied Linguistics, 9 (18), 183196.

Tran, T. N.P., \& Tran, T. Q. (2017). Attitudes towards the Learning of culture in English language learning among Vietnamese high school students. Proceedings of the Third International TESOL Conference Promoting ELT: Diverse Perspectives and New Horizons at Ho Chi Minh City University of Education (pp.233-246). Ho Chi Minh City: Ho Chi Minh City University of Education Publishing House.

Tran. T. Q., (2018). The roles of technology in promoting English-majored students' learner autonomy: A Critical Look at HUTECH Context. Proceedings of Conference on Technology and Science 2018 at Ho Chi Minh City University of Technology (pp.344-348). Ho Chi Minh City: Science and Technology Publishing House.

Tran, T. Q., \& Duong, T. M., (2018). EFL learners' perceptions of factors influencing learner autonomy development. Kasetsart Journal of Social Sciences, 39(1),1-6. DOI: 10.1016/j.kjss.2018.02.009

Tran, T. Q., \& Seepho, S. (2016). EFL learners' attitudes toward intercultural communicative language teaching and their intercultural communicative competence development. Journal of English Studies, $11,1-40$.

Tran. T. Q., \& Nguyen, T. G. (2017). The Use of English Vocabulary Learning Strategies among Vietnamese High School Students. Proceedings of the Third International TESOL Conference Promoting ELT: Diverse Perspectives and New Horizons at Ho Chi Minh City University of Education (pp.223-232). Ho Chi Minh City: Ho Chi Minh City University of Education Publishing House.

Tran. T. Q., \& Vo. D. Q. (2019). Tertiary English majors' perceptions of the importance of learner autonomy and autonomous language learning strategy use. Proceedings of the International conference: Autonomy and motivation for language learning in the interconnected world at Ho Chi Minh City University of Technology and Education (pp.102-113). Ho Chi Minh City: Vietnam National University - Ho Chi Minh Press.

Tran T. Q., Duong, T. M., \& Huynh, N. T. T. (2019). Attitudes toward the use of TELL tools in English language learning among Vietnamese tertiary English majors. VNU Journal of Social Sciences and Humanities, 5(5), 581-594. DOI: http://dx.doi.org/10.1172/vjossh.v5i5.498

Vanijdee, A. (2003). Thai distance English learners and learner autonomy. Open Learning, 18(1), 75-84.

Willis, D. (1990). The lexical syllabus: A new approach to language teaching. London: Collins ELT. 